\title{
A novel E. coli strain shows controllable leakiness for extracellular production of recombinant proteins
}

\author{
Jens Kastenhofer ${ }^{1}$, Lukas Rettenbacher ${ }^{1}$, Lukas Feuchtenhofer ${ }^{2}$, Jürgen Mairhofer ${ }^{2}$, and \\ Oliver Spadiut ${ }^{1}$
}

${ }^{1}$ Vienna University of Technology

${ }^{2}$ enGenes Biotech GmbH

April 28, 2020

\begin{abstract}
Recombinant proteins in Escherichia coli are usually expressed inside the cell. With the growing interest in continuous cultivation, secretion of product to the medium is not only a benefit, but a necessity in future bioprocessing. In this study, we present the X-press strain, a novel E. coli production host for growth decoupled, extracellular recombinant protein production. We investigated the effect of the process parameters temperature and specific glucose uptake rate (qS) on the strain's growth, productivity, lysis and leakiness, to find the parameter space allowing extracellular protein production. Two model proteins were used, Protein A and a VHH single-domain antibody, and performance was compared to the industrial standard strain BL21(DE3). We show that inducible growth repression in the X-press strain greatly mitigates the effect of metabolic burden under different process conditions. Furthermore, temperature and qS were used to control productivity and leakiness. In the X-press strain, extracellular Protein A and VHH titer reached up to $349 \mathrm{mg} / \mathrm{g}$ and $19.6 \mathrm{mg} / \mathrm{g}$, respectively, comprising up to $90 \%$ of total soluble product, while keeping cell lysis at a minimum. Our findings demonstrate that the X-press strain constitutes a valuable host for extracellular production of recombinant protein with E. coli.
\end{abstract}

\begin{abstract}
Recombinant proteins in Escherichia coli are usually expressed inside the cell. With the growing interest in continuous cultivation, secretion of product to the medium is not only a benefit, but a necessity in future bioprocessing. In this study, we present the X-press strain, a novel $E$. coli production host for growth decoupled, extracellular recombinant protein production. We investigated the effect of the process parameters temperature and specific glucose uptake rate $\left(q_{S}\right)$ on the strain's growth, productivity, lysis and leakiness, to find the parameter space allowing extracellular protein production. Two model proteins were used, Protein $\mathrm{A}$ and a VHH single-domain antibody, and performance was compared to the industrial standard strain BL21(DE3). We show that inducible growth repression in the X-press strain greatly mitigates the effect of metabolic burden under different process conditions. Furthermore, temperature and $q_{S}$ were used to control productivity and leakiness. In the X-press strain, extracellular Protein A and VHH titer reached up to 349 $\mathrm{mg} / \mathrm{g}$ and $19.6 \mathrm{mg} / \mathrm{g}$, respectively, comprising up to $90 \%$ of total soluble product, while keeping cell lysis at a minimum. Our findings demonstrate that the X-press strain constitutes a valuable host for extracellular production of recombinant protein with $E$. coli .
\end{abstract}

Keywords

continuous manufacturing; leakiness; outer membrane integrity; periplasmic protein release; secretion 


\section{Introduction}

Escherichia coli is a widely used expression host for recombinant protein production. Its advantages lie in short doubling times, growth on cheap media to high cell densities and straightforward cloning procedures (Kleiner-Grote, Risse, \& Friehs, 2018; Rosano \& Ceccarelli, 2014; Yoon, Kim, \& Kim, 2010). However, the product is usually expressed inside the cell, which requires cell disruption in downstream processing, leading to release of unwanted host cell proteins and other contaminants, like lipids and DNA (Balasundaram, Harrison, \& Bracewell, 2009). If the target protein is produced as insoluble inclusion bodies (IBs), additional IB processing is needed.

Especially with the growing interest in continuous manufacturing (C. Chen, Wong, \& Goudar, 2018; Kateja, Agarwal, Hebbi, \& Rathore, 2017), extracellular production is an important enabler for future bioprocessing with E. coli. Secretion of recombinant protein to the medium furthermore enhances solubility, stability and biological activity of the product (Mergulhão \& Monteiro, 2007). This can be achieved either by onestep-secretion (directly from the cytoplasm to the extracellular space) via the T1SS or T3SS system, or by two-step-secretion: In the first step, the protein is directed through the inner membrane via the Sec- or Tat-pathway. In the second step, the outer membrane (OM) is made permeable, or "leaky", to release the product to the medium (Kleiner-Grote et al., 2018). Numerous studies on how to increase leakiness during cultivation exist and several reviews cover this research in detail (Kleiner-Grote et al., 2018; Mergulhão, Summers, \& Monteiro, 2005; Yoon et al., 2010).

One approach to increase leakiness is chemical permeabilization by addition of media supplements, like Triton-X, glycine or EDTA. However, those additives usually have detrimental effects on the viability of the cells and might harm the product (Kleiner-Grote et al., 2018). Another approach is the generation of leaky $E$. coli mutants. Many expression systems that show permanently high leakiness have been engineered to date. Their outer membrane structure is usually altered by mutations in cell envelope genes and signal peptides are optimized for higher translocation efficiency (Kleiner-Grote et al., 2018; Zhou, Lu, Wang, Selvaraj, \& Zhang, 2018). However, detailed process information at bioreactor scale is often missing for these strains.

Another reported strategy is the enhancement of OM permeability via temperature or specific growth rate $(\mu)$. Shokri, Sanden, and Larsson (2002) showed that growth rate dependent changes in the membrane composition have an effect on protein leakage. In their study, in continuous cultivation of E. coli W3110, leakiness had an optimum at a dilution rate of $0.3 \mathrm{~h}^{-1}$ and declined upon lowering or increasing $\mu$. Similar results were obtained in fed-batch studies of W3110 (Voulgaris, Finka, Uden, \& Hoare, 2015 ) and a K12 derivate (Bäcklund et al., 2008), in which an increase in $\mu$ led to enhanced leakiness. Contrarily, Rinas and Hoffmann (2004) stated that $\mu$ had no significant effect on periplasmic protein release during heat induction of $E$. coli TG1 strains. In another fed-batch study using a C41(DE3) strain, it has even been stated that $\mu$ and leakiness are inversely correlated (Wurm, Marschall, Sagmeister, Herwig, \& Spadiut, 2017). Adverse reports can also be found about the influence of temperature on OM leakiness for different $E$. coli strains. While Rodríguez-Carmona et al. (2012) found that leakage of a Fab was enhanced at lower temperatures, several other studies suggest that increased temperature drives periplasmic protein release (Rinas \& Hoffmann, 2004; Wurm, Marschall, et al., 2017; Wurm, Slouka, Bosilj, Herwig, \& Spadiut, 2017). Controlling leakiness via temperature and $\mu$ is an interesting approach, since it does not require alteration of the chemical environment and is easy to implement, however, the contrary results in the aforementioned studies illustrate that the mechanisms that temperature and $\mu$ exert on outer membrane leakiness might depend on a variety of factors, like the strain, product or promoter, and are not fully understood yet.

In this study, we investigated the influence of the process parameters cultivation temperature and specific glucose uptake rate $\left(q_{S}\right.$, linked to $\mu$ via the biomass yield $\left.Y_{X / S}\right)$ on OM leakiness of a novel E. coliexpression host. The X-press strain is a proprietary expression technology recently developed by enGenes Biotech GmbH (Mairhofer, Striedner, Grabherr, \& Wilde, 2016; Stargardt, Feuchtenhofer, Cserjan-Puschmann, Striedner, \& Mairhofer, 2020). It is derived from BL21(DE3) and carries a genomically integrated sequence coding for the bacteriophage-derived RNA polymerase inhibitor Gp2 under control of thearaB promoter. This protein from the T7 phage inhibits the host RNA polymerase, while the T7 RNA polymerase stays unaffected. Thus, upon 
induction with L-arabinose, host mRNA levels and cell proliferation are reduced, while IPTG-induced target protein expression is enhanced. This approach to decouple growth from recombinant protein production has already been shown to increase specific yield and product quality (Lemmerer et al., 2019; Stargardt et al., 2020). In previous experiments, the X-press strain showed high tendency to leak periplasmic protein to the medium (Stargardt et al., 2020). Therefore, in the present research, we further investigated its response to the process parameters temperature and $q_{S}$, both known to affect leakiness of other E. colistrains, in fedbatch cultivations. We performed a screening Design of Experiments (DoE) to find the adequate parameter space for enhancing leakiness while maintaining high productivity and viability. We compared the X-press strain to the industrial standard strain BL21(DE3), using two industrially relevant model proteins: Protein A (SpA) fromStaphylococcus aureus and a $\mathrm{VHH}$ sdAb ( VHH). The processes were analyzed with respect to $Y_{X / S}$, productivity, lysis and leakiness. With this holistic approach, we aimed at 1) characterization of a novel E. coli expression host for growth decoupled protein secretion and 2) finding the parameter space that allows tight control of leakiness and productivity for extracellular recombinant protein production.

Materials and Methods

\section{Strains}

Two E. coli strains were used in this study: the X-press strain, a BL21(DE3) derivate patented by enGenes Biotech GmbH (Mairhofer et al., 2016; Stargardt et al., 2020), and a state-of-the-art BL21(DE3) strain (New England Biolabs, Ipswich, MA). The X-press strain carries a genomically integrated sequence coding for Gp2, a protein repressing cell growth by inhibition of RNA polymerase. Its expression is induced by L-arabinose, which cannot be degraded by X-press due to a knockout of the ara $A B C D$ operon. For determination of cell growth repression solely induced by Gp2 expression, the plasmid free X-press strain was used. For recombinant protein production, both strains were transformed with a pET30a plasmid containing a cer sequence for enhanced plasmid stability (Bower \& Prather, 2009) and a kanamycin resistance marker. The plasmid carried the gene coding for 1) the IgG-binding domains of Protein A from Staphylococcus aureus (SpA) with the pelB signal sequence or 2) the anti-TNFRI VHH single domain antibody DOM101 with the ompA signal sequence (Chatel et al., 2014). Both proteins were His-tagged at the C-terminus. Protein sequences are listed in Supporting Information 1.

\section{Media}

The semi-defined medium for the pre-culture contained $9.00 \mathrm{~g} / \mathrm{L}$ glucose, $3.00 \mathrm{~g} / \mathrm{L} \mathrm{KH}_{2} \mathrm{PO}_{4}, 4.58 \mathrm{~g} / \mathrm{L}$ $\mathrm{K}_{2} \mathrm{HPO}_{4}, 0.30 \mathrm{~g} / \mathrm{L}$ peptone, $0.15 \mathrm{~g} / \mathrm{L}$ yeast extract, $0.75 \mathrm{~g} / \mathrm{L}$ sodium citrate dihydrate, $0.30 \mathrm{~g} / \mathrm{L} \mathrm{MgSO} 4$ [?] $7 \mathrm{H}_{2} \mathrm{O}, 0.03 \mathrm{~g} / \mathrm{L} \mathrm{CaCl} 2$ [?] $2 \mathrm{H}_{2} \mathrm{O}, 1.35 \mathrm{~g} / \mathrm{L}\left(\mathrm{NH}_{4}\right)_{2} \mathrm{SO}_{4}, 1.11 \mathrm{~g} / \mathrm{L} \mathrm{NH}_{4} \mathrm{Cl}, 50 \mathrm{mg} / \mathrm{L}$ kanamycin and $150 \mu \mathrm{L} / \mathrm{L}$ of a solution containing $40.00 \mathrm{~g} / \mathrm{L} \mathrm{FeSO}_{4}$ [?] $7 \mathrm{H}_{2} \mathrm{O}, 10.00 \mathrm{~g} / \mathrm{L} \mathrm{MnSO}_{4}$ [?] $\mathrm{H}_{2} \mathrm{O}, 10.00 \mathrm{~g} / \mathrm{L} \mathrm{AlCl}_{3}$ [?] $6 \mathrm{H}_{2} \mathrm{O}$, $7.30 \mathrm{~g} / \mathrm{L} \mathrm{CoCl}_{2}$ [?] $6 \mathrm{H}_{2} \mathrm{O}, 2.00 \mathrm{~g} / \mathrm{L} \mathrm{ZnSO}_{4}$ [?] $7 \mathrm{H}_{2} \mathrm{O}, 2.00 \mathrm{~g} / \mathrm{L} \mathrm{NaMoO}_{4}$ [?] $2 \mathrm{H}_{2} \mathrm{O}, 1.00 \mathrm{~g} / \mathrm{L} \mathrm{CuCl}_{2}$ [?] $2 \mathrm{H}_{2} \mathrm{O}$, $0.50 \mathrm{~g} / \mathrm{L} \mathrm{H}_{3} \mathrm{BO}_{3}$. For bioreactor cultivations, defined minimal media according to DeLisa, Li, Rao, Weigand, and Bentley (1999) was used, with glucose as carbon source. The initial glucose concentration was $20 \mathrm{~g} / \mathrm{L}$ and the substrate feed had a glucose concentration of $400 \mathrm{~g} / \mathrm{L}$.

\section{Bioreactor cultivations}

For the pre-culture, $500 \mathrm{~mL}$ of semi-defined medium were inoculated with a frozen stock in a $2500 \mathrm{~mL}$ High Yield shake flask and incubated for $16 \mathrm{~h}$ at $37^{\circ} \mathrm{C}$ and $230 \mathrm{rpm}$ in an Infors HR Multitron incubator (Infors, Bottmingen, Switzerland). 
The plasmid free X-press strain was cultivated in a stainless steel bioreactor with a working volume of $10 \mathrm{~L}$ (Biostat Cplus, Sartorius, Göttingen, Germany). The batch volume was 5 L. The culture broth was supplied with a mixture of air and pure oxygen at $10 \mathrm{~L} / \mathrm{min}$ and stirred constantly at $1200 \mathrm{rpm}$. Dissolved oxygen (DO) was monitored using a fluorescence electrode (Visiferm DO120, Hamilton, Reno, NV, USA) and kept above $35 \%$ by adjusting the amount of added pure oxygen. $\mathrm{pH}$ was monitored with an Easyferm electrode (Hamilton) and kept constant at 7.00 via addition of $\mathrm{NH}_{4} \mathrm{OH}(12.5 \%)$. The temperature was controlled with the built-in heat jacket and kept at $37^{\circ} \mathrm{C}$, except during induction (described below).

The recombinant protein production processes were carried out in a DASGIP parallel reactor system (Eppendorf, Hamburg, Germany) with four vessels containing $2 \mathrm{~L}$ working volume, aerated at $2 \mathrm{~L} / \mathrm{min}$. The batch volume was $1 \mathrm{~L}$. Gas mixing and control of $\mathrm{DO}, \mathrm{pH}$ and temperature (via heat blanket and cooling finger) were done analogously to the cultivations in the stainless steel bioreactor described above.

The batch was started by inoculating minimal media (90\% of the batch volume) with the preculture (10\% of the batch volume). Once glucose was depleted (detected by a DO spike), substrate was fed to reach a cell dry weight concentration of $50 \mathrm{~g} / \mathrm{L}$ and $30 \mathrm{~g} / \mathrm{L}$ in the growth repression and recombinant protein production processes, respectively. Subsequently, expression of Protein A or VHH was induced by addition of $0.5 \mathrm{mM}$ or $0.25 \mathrm{mM}$ IPTG, respectively. Additionally, Gp2 expression in the X-press strain was induced by adding $100 \mathrm{mM}$ L-arabinose.

\section{Design of Experiments}

To study the effect of temperature and $q_{S}$ on growth, productivity, lysis and leakiness during SpA production, a full-factorial screening DoE was performed. Since growth of the X-press strain is repressed by Gp2 expression during induction, we chose to apply a constant substrate feed rate in our experiments. In the DoE, this is reflected in the first factor as the specific glucose uptake rate with respect to biomass at start of induction $\left(q_{S, 0}\right)$. It was set to $0.13,0.25$ and $0.50 \mathrm{~g} / \mathrm{g} / \mathrm{h}$, respectively. Temperature during induction, the second factor, was 25,30 or $35^{\circ} \mathrm{C}$, respectively. The different parameter settings are hereafter referred to as "temperature $\left[{ }^{\circ} \mathrm{C}\right] /$ glucose uptake rate $[\mathrm{g} / \mathrm{g} / \mathrm{h}]$ ", e.g. 30/0.25. Thus, the five factor combinations for the SpA cultivations were: $25 / 0.13,25 / 0.5,30 / 0.25 /, 35 / 0.13,35 / 0.5$. At $q_{S, O}=0.5 \mathrm{~g} / \mathrm{g} / \mathrm{h}$, the physiological capabilities of the $\mathrm{X}$-press strain were far exceeded (manifested in glucose accumulation and lysis, see Supporting Information 2) and linear regression did not result in significant model coefficients, thus we decided to omit the data of these experiments from further analysis in this study. In addition to the SpA cultivations, the growth arrest experiment with the plasmid free X-press strain was conducted at conditions 30/0.13. Furthermore, the process conditions leading to the highest productivity during SpA cultivations were repeated in both strains containing the plasmid with the VHH sequence.

\section{Analysis of biomass yield}

Biomass was quantified gravimetrically in triplicate by centrifuging $2 \mathrm{~mL}$ of culture (4000 rcf, $10 \mathrm{~min}$ ), washing the pellets with $0.9 \%(\mathrm{w} / \mathrm{v}) \mathrm{NaCl}$ and drying them at $105^{\circ} \mathrm{C}$ for $72 \mathrm{~h}$. Dry biomass concentration was then determined by weighing the dry pellets. Concentrations of residual glucose and L-arabinose in the cell-free supernatant were analyzed via HPLC (UltiMate 3000; Thermo Fisher, Waltham, MA) with a Supelcogel C-610H column (Supelco, Bellefonte, PA). The eluent was $0.1 \% \mathrm{H}_{3} \mathrm{PO}_{4}$ and the flow rate constant at $0.5 \mathrm{~mL} / \mathrm{min}$.

$Y_{X / S}$ was calculated for the time before induction and after induction, respectively (Equations $1 \& 2$ ). For this, only the net biomass accumulation, corrected for intracellular product, was taken into account. 


\begin{tabular}{ll}
$Y_{X / S, 0}=\frac{m_{X, i}-m_{X, 0}}{m_{S, i}}$ & $(1)$ \\
\hline$Y_{X / S, n}=\frac{m_{X, n}-m_{X, i}}{m_{S, n}-m_{S, i}}$ & $(2)$ \\
\hline
\end{tabular}

$Y_{X / S, 0}$ is the biomass yield before induction $[\mathrm{g} / \mathrm{g}] ; m_{X, i}$ is the biomass at time of induction $[\mathrm{g}] ; m_{X, 0}$ is the biomass at time of inoculation $[\mathrm{g}] ; m_{S, i}$ is the consumed sugar at time of induction $[\mathrm{g}] ; Y_{X / S, n}$ is the biomass yield after induction at time point $n[\mathrm{~g} / \mathrm{g}] ; m_{X, n}$ is the biomass after induction at time point $n[\mathrm{~g}] ; m_{S, n}$ is the consumed sugar after induction at time point $n[\mathrm{~g}]$.

\section{Analysis of lysis}

Under the assumption that released DNA is proportional to the amount of lysed cells, quantification of lysis was adapted from Klein et al. (2015). For our calculations, we assumed a cellular DNA content of 31 $\mathrm{mg} / \mathrm{g}$, which was taken from literature (Neidhardt \& Umbarger, 1996). Double strand DNA in the culture supernatant was measured in triplicate with the Quant-iT PicoGreen ${ }^{\circledR}$ dsDNA Assay Kit (Thermo Fisher). The accumulation of DNA was corrected with a degradation rate as described in Supporting Information 3. The amount of lysed cells $\left(x_{l}\right)$ was calculated according to Klein et al. (2015) and expressed as percent of total biomass concentration as shown in Equation 3:

$$
\underline{\text { lysed cells }=\frac{x_{l}}{x_{l}+x} * 100 \quad(3)}
$$

$x_{l}$, amount of lysed biomass $[\mathrm{g} / \mathrm{L}] ; x$, cell dry weight $[\mathrm{g} / \mathrm{L}]$.

\section{Product analysis}

For SpA quantification, $10 \mathrm{~mL}$ culture were centrifuged for 10 minutes at $15,000 \mathrm{rcf}$ and $4^{\circ} \mathrm{C}$. The supernatant was aliquoted and stored at $-20^{\circ} \mathrm{C}$. The cell pellet was re-suspended in $35 \mathrm{~mL}$ of TRIS-buffer $(100 \mathrm{mM}$ TRIS, $10 \mathrm{mM}$ EDTA, pH 7.4). This suspension was homogenized in an Emulsiflex C3 homogenizer (Avestin, Ottawa, ON, Canada) (5 passages, $1000 \mathrm{bar}$ ) and the sample was then centrifuged for 15 minutes $\left(20,000 \mathrm{rcf}, 4^{\circ} \mathrm{C}\right)$. The pellet was stored at $-20^{\circ} \mathrm{C}$. Intracellular soluble SpA content and SpA content in the cell-free culture supernatant were quantified in triplicate by HPLC analysis using a reversed phase column (BioResolve RP mAb Polypheyl; Waters, Milford, MA) and a gradient of acetonitrile and water, both supplemented with $0.1 \%(\mathrm{v} / \mathrm{v})$ trifluoroacetic acid.

VHH quantification was done analogously, with the exception that the cell pellet was sonicated in MESBuffer (100 mM MES, $10 \mathrm{mM}$ EDTA, pH 6.0) and HPLC analysis was performed with a cation exchange column (BioResolve SCX mAb; Waters). The loading buffer was $20 \mathrm{mM}$ MES, pH 6.0 and VHH was eluted with a $\mathrm{Na}^{+}$gradient.

Inclusion body formation of VHH was analyzed qualitatively by SDS-PAGE. For this, the pellet obtained after homogenization was resuspended in $20 \mathrm{~mL}$ of Buffer A (50 mM TRIS, $0.5 \mathrm{M} \mathrm{NaCl}, 0.02 \%$ Tween, $\mathrm{pH}$ 8.0) and then centrifuged for 10 minutes $(10,000 \mathrm{rcf}$, $4 \operatorname{deg} \mathrm{C})$. The resulting pellet was washed in $20 \mathrm{~mL}$ Buffer B (50 mM TRIS, $5 \mathrm{mM}$ EDTA, pH 8.0) and $2 \mathrm{~mL}$ aliquots were centrifuged for 10 minutes (10,000 rcf, $4 \mathrm{deg}$ ). Subsequently, the pellet was resuspended in $1 \mathrm{~mL}$ ultrapure water, diluted with $1.5 \mathrm{x}$ Laemmli buffer. A VHH standard $(5 \mathrm{~g} / \mathrm{L})$ was diluted in $2 \mathrm{x}$ Laemmli buffer. The samples and standard were then incubated at $95 \mathrm{deg} \mathrm{C}$ for 15 minutes. $10 \mu \mathrm{L}$ of sample and $5 \mu \mathrm{L}$ of standard were loaded onto precast SDS gels (8-16\%, Mini-PROTEAN TGX; Bio-Rad, Hercules, CA). Gels were run at $120 \mathrm{~V}$ for 30 minutes in a MiniPROTEAN Tetra-Cell (Bio-Rad) and stained with Coomassie Blue. Images were captured and analyzed using the software Image Lab (Bio-Rad). 


\section{Calculation of leakiness}

The quotient of soluble extracellular and total intracellular product (leakiness) in percent was calculated using Equation 4:

$\overline{\text { leakiness }=\frac{w_{\text {Pin }}}{w_{\text {Pex }}+w_{\text {Pin }}} * 100 \quad(4)}$

$w_{P i n}$, biomass specific intracellular product concentration $[\mathrm{mg} / \mathrm{g}] ; w_{P e x}$, biomass specific extracellular product concentration $[\mathrm{mg} / \mathrm{g}]$.

Results and Discussion

The process parameters temperature and $\mu$ are important factors in bioprocess development and are known to have an impact on leakiness of different E. coli strains (Table 1). Although conclusive, mechanistic understanding is still missing. In this study, we performed characterization of the novel $E$. coli X-press strain in fed batch cultivations by investigating the influence of temperature and $q_{S, O}\left(q_{S}\right.$ at the beginning of induction) on growth, productivity, lysis and leakiness, with the aim of understanding the behavior of the strain and finding a cultivation strategy that allows the successful control of product location. For comparison of the X-press strain to a benchmark strain, we choseE. coli BL21(DE3), since it is the most widely used E. coli strain for recombinant protein production (Jia \& Jeon, 2016; Rosano, Morales, \& Ceccarelli, 2019). Three combinations of cultivation temperature and $q_{S, 0}(30 / 0.25,25 / 0.13,35 / 0.13)$ were first applied using the model protein SpA. The most favorable production conditions were then tested again with the second model protein VHH.

\section{Impact of process parameters on $Y_{X / S}$}

It has long been known that heterologous expression in plasmid-based $E$. coli systems has a grave impact on cell physiology, widely known as metabolic burden (Mairhofer, Scharl, Marisch, Cserjan-Puschmann, \& Striedner, 2013). This burden is often associated with a decrease in growth rate and ultimately cell lysis (Bentley, Mirjalili, Andersen, Davis, \& Kompala, 1990; Bienick et al., 2014). We assessed the impact of the selected process parameters on growth by measuring $Y_{X / S}$. To investigate the induced growth repression in the X-press strain without metabolic burden from recombinant product formation, we performed a cultivation without an exogenous plasmid and solely inducing Gp2 expression by addition of L-arabinose. After induction, $Y_{X / S}$ was reduced by half from 0.48 in the uninduced state to levels between 0.24 and 0.27 , remaining almost constant throughout the cultivation (Figure 1A). We assumed that any additional reduction of $Y_{X / S}$ is caused by the metabolic burden of heterologous gene expression. During production of $\mathrm{SpA}$ in cultivation $25 / 0.13$, the reduction of $Y_{X / S}$ was similar to the "basal" reduction by Gp2 expression, thus the metabolic load of SpA expression had little effect on growth. An additional reduction was observed at higher temperature and $q_{S, 0}$. In both cultivations 30/0.25 and 35/0.13, $Y_{X / S}$ decreased throughout the cultivation to values between 0.03 and 0.1 . Hence, the metabolic load of recombinant product expression still affected growth of the X-press strain, but it was largely mitigated by induced growth repression. Contrarily, in the reference strain BL21(DE3), $Y_{X / S}$ varied greatly between different cultivation conditions during SpA production (Figure 1B). It decreased at higher induction temperature, so that at $25^{\circ} \mathrm{C}$, biomass yield of BL21(DE3) was least affected, while at $35^{\circ} \mathrm{C}$, growth was fully arrested. This behavior might stem from an increase in target gene transcript levels competing with host mRNA at elevated temperatures (C. S. Shin, Hong, Bae, \& Lee, 1997; Vind, Sorensen, Rasmussen, \& Pedersen, 1993). 


\section{Impact of process parameters on productivity}

At low temperature and $q_{S, 0}(25 / 0.13)$, biomass specific, soluble SpA titer after $12 \mathrm{~h}$ was lowest in both strains at $123 \pm 4$ and $113 \pm 7 \mathrm{mg} / \mathrm{g}$ in X-press and BL21(DE3), respectively (Figure 2). Raising the temperature at low $q_{S, 0}$ from 25 to $35^{\circ} \mathrm{C}$ drove $\mathrm{SpA}$ expression, so that the total titer after $12 \mathrm{~h}$ increased to $314 \pm 6$ and $240 \pm 9 \mathrm{mg} / \mathrm{g}$ in X-press and BL21(DE3), respectively. It has been shown that the overall protein synthesis rate as well as plasmid replication are dependent on temperature (Farewell \& Neidhardt, 1998; Hoffmann \& Rinas, 2001). In our experiments, $35^{\circ} \mathrm{C}$ induction temperature might have resulted in a higher plasmid copy number and concomitant high levels of target gene transcripts, competing for ribosomes with native mRNA, thus increasing recombinant protein expression and decreasing the growth rate. At $25^{\circ} \mathrm{C}$, this reaction was possibly shifted in favor of host mRNA due to lower levels of plasmids, resulting in low productivity and little metabolic burden. The highest specific SpA titer was achieved in cultivation 30/0.25, with $387 \pm 12$ and $351 \pm 17 \mathrm{mg} / \mathrm{g}$ in X-press and BL21(DE3), respectively, which was expected, since more carbon was available for product formation. However, yield reduction in BL21(DE3) at these process conditions was less than at $35^{\circ} \mathrm{C}$, indicating that a decrease in growth rate was not only mediated by foreign protein content, but as hypothesized, by the underlying temperature-dependent mechanisms at transcript level.

An advantage of induced, growth decoupled protein production in the X-press strain is enhanced resource allocation towards recombinant protein. Although in this study, total soluble specific titers did not improve as much as with previously reported products (Lemmerer et al., 2019; Stargardt et al., 2020), specific SpA titers were up to $30 \%$ higher in the X-press strain at the end of cultivation compared to the reference strain.

\section{Impact of process parameters on lysis and leakiness}

No lysis was detected under any condition during SpA production with BL21(DE3). The X-press strain did not lyse at low $q_{S, 0}$, however, in cultivation $30 / 0.25$, lysis increased towards the end of fermentation, so that $7 \%$ of cells were lysed after $12 \mathrm{~h}$ (Figure 3). Thus, in the later stages of this cultivation, the amount of leaked protein is biased by product release by lysis. Nonetheless, the X-press strain showed higher overall leakiness in response to increased temperature and $q_{S, 0}$ compared to BL21(DE3). In cultivation 25/0.13, leakiness reached up to $29 \%$ in X-press (Figure 2A), while the reference strain leaked no product at all (Figure 2B). Solely increasing the temperature to $35^{\circ} \mathrm{C}$ greatly enhanced $\mathrm{OM}$ permeability in both strains, so that after $12 \mathrm{~h}, 82 \%$ and $55 \%$ of SpA were leaked to the supernatant in X-press and BL21(DE3), respectively. Simultaneously increasing temperature and $q_{S, 0}$ (cultivation 30/0.25) led to high leakiness in both strains as well. Up to $90 \%$ and $56 \%$ of SpA were released to the medium in X-press and BL21(DE3), respectively. Interestingly, the combined effect of temperature and $q_{S, 0}$ on leakiness in the reference strain was the same as solely increasing the temperature. In the X-press strain, on the other hand, OM permeability was more sensitive to the simultaneous increase in temperature and $q_{S, O}$. This manifested in much faster product release in cultivation 30/0.25 than in the other cultivations (Figure 2). However, cell lysis commenced after $8 \mathrm{~h}$ (Figure 3), which is likely due to high stress caused by the high product formation rate.

From the results obtained in the SpA fermentations we deducted different approaches to extracellular production in the X-press strain: (1) Low $q_{S, 0}$ and high temperature are beneficial for maintaining a viable culture and boosting productivity and leakiness over extended fermentation times; (2) moderately increasing temperature and $q_{S, 0}$ rapidly enhances leakiness and productivity, but high viability might not be sustained for long fermentation times. Either scenario would allow for efficient capture of the product from the culture supernatant for simplified downstream processing. Controlling leakiness via temperature and $q_{S, O}$ is also possible in the reference strain BL21(DE3). However, these process parameters have a grave impact on productivity as well, thus product location cannot be uncoupled from productivity. For BL21(DE3), this is a double-edged sword: increasing temperature and specific glucose uptake rate greatly enhanced SpA titer, but the cells did not leak more than $60 \%$ of product to the medium. Hence, capturing the target protein from the cells or from the medium, respectively, would result in large product losses in both scenarios. 
Table 1 shows an overview of previous studies on the effect of cultivation temperature and $q_{S}$ on leakiness in different E. coli hosts, that have not been engineered for the purpose of protein secretion. There is no fully consistent behavior among different E. coli strains. In fact, differences exist even between similar strains. Reasons for this might be the used promoter system or product and resulting differences in the energy requirement, resource handling within the cell and, ultimately, membrane structure and properties. Other environmental factors, like medium composition and aeration, were also shown to affect OM permeability (Orr et al., 2012; Ukkonen, Veijola, Vasala, \& Neubauer, 2013), which makes a direct comparison between different studies even harder. Our results agree with most studies listed in Table 1 that showed a positive correlation between leakiness and both temperature and $q_{S}$. This might be due to a change in fatty acid composition and therefore rigidity of the cell envelope (Arneborg, Salskov-Iversen, \& Mathiasen, 1993; Shokri et al., 2002) or a change in OM proteins that might influence the transport to the medium (Bäcklund et al., 2008). However, given the inconsistent results in literature, more rigorous examination of the relationship between expression system, process parameters, like temperature and $q_{S}$, membrane properties and resulting leakiness is needed to gain more mechanistic understanding, not only for the strains used in this study, but for all future research on this topic.

In leaky mutants, the increased secretion across the OM is most often due to mutations in genes related to membrane proteins, lipopolysaccharides or the peptidoglycan layer (Z. Y. Chen et al., 2014; Müller, Wetzel, Flaschel, Friehs, \& Risse, 2016; Orr et al., 2012; H. D. Shin \& Chen, 2008; Zhou et al., 2018). These genes were not manipulated during the construction of the X-press strain. Thus, the question is raised, how Gp2 expression can have an impact on membrane properties. Clearly, inhibiting the host RNA-polymerase, a most central enzyme in cell proliferation, can disturb practically any metabolic pathway. So far, the chain of causality between Gp2 expression and increased membrane permeability remains obscure. Currently, we are investigating the effects of Gp2 at the transcriptome and proteome level.

\section{Production of VHH in BL21(DE3) and X-press}

The cultivation conditions that resulted in the highest productivity of SpA in each strain (30/0.25) were repeated with the second model protein, $\mathrm{VHH}$, and fermentations were assessed after $14 \mathrm{~h}$ induction time. The results are summarized in Table 2. The biomass growth in both strains was less affected compared to the corresponding SpA cultivations. In the X-press strain, the biomass yield reduction was close to the "basal" growth repression by Gp2 induction. In BL21(DE3), biomass yield was reduced by less than 0.1 $\mathrm{g} / \mathrm{g}$. This was likely due to the much lower amount of produced recombinant product compared to $\mathrm{SpA}$ and, as a result, a lower metabolic burden (Bentley et al., 1990; Bienick et al., 2014). Total productivity of soluble $\mathrm{VHH}$ was greatly enhanced in the X-press strain compared to the reference strain. Although inclusion body formation was detected in both strains (Supporting Information 4), the induced growth repression and enhanced secretion ability of the X-press strain seemed to have a beneficial effect on solubility of VHH, which is difficult to fold due to its disulfide bridges (de Marco, 2009; Liu \& Huang, 2018). Also the amount of secreted protein was greatly improved in the X-press strain and was comparable to the SpA cultivations, although lysis was negligible during VHH production. Overall, the cultivations with the second model protein confirmed that the selected settings of process parameters $\left(T=30^{\circ} \mathrm{C}, q_{S, 0}=0.25 \mathrm{~g} / \mathrm{g} / \mathrm{h}\right)$ lead to efficient product secretion in the X-press strain, while product location in BL21(DE3) is inefficiently partitioned both inside and outside the cell. The issue of insoluble product aggregation might be addressed in further development, for instance by inducer titration or similar approaches, to fine tune expression levels and thus further enhance soluble productivity.

\section{Conclusion}

We could demonstrate the applicability of the novel E. coliX-press strain for extracellular production of recombinant proteins. We narrowed down the design space, in which extracellular protein production is favored without sacrificing viability: cultivation temperatures between 30 and $35^{\circ} \mathrm{C}$ and $q_{S, O}$ between 0.13 and $0.25 \mathrm{~g} / \mathrm{g} / \mathrm{h}$ enhanced both leakiness and productivity while keeping cell lysis to a minimum. The process 
parameters both individually and interactively affected total product titer and leakiness in a positive manner in both investigated expression hosts. By inducible growth repression, the novel E. coli X-press strain showed less susceptibility to the metabolic burden of recombinant protein production and thus allows for tighter process control due to reduced variability across different process conditions. Lastly, we showed that the $\mathrm{X}$-press strain can achieve high titers of different classes of recombinant protein and leaks up to $90 \%$ of all soluble product. Therefore, this strain is a promising candidate for extracellular protein production in current fed-batch applications or for future continuous manufacturing. Further research should be directed towards the relationship between different expression systems, process parameters and their implications on periplasmic protein release.

\section{Acknowledgements}

The authors gratefully acknowledge the funding of this research by the Vienna Business Agency (Wirtschaftsagentur Wien) [grant number 1898413] and the TU Wien Bibliothek for financial support through its Open Access Funding Program.

References

Arneborg, N., Salskov-Iversen, A., \& Mathiasen, T. (1993). The effect of growth rate and other growth conditions on the lipid composition ofEscherichia coli. Applied Microbiology and Biotechnology, 39 (3), 353-357. doi:10.1007/bf00192091

Bäcklund, E., Reeks, D., Markland, K., Weir, N., Bowering, L., \& Larsson, G. (2008). Fedbatch design for periplasmic product retention inEscherichia coli . Journal of Biotechnology, 135 (4), 358-365. doi:10.1016/j.jbiotec.2008.05.002

Balasundaram, B., Harrison, S., \& Bracewell, D. G. (2009). Advances in product release strategies and impact on bioprocess design. Trends in Biotechnology, 27 (8), 477-485. doi:10.1016/j.tibtech.2009.04.004

Bentley, W. E., Mirjalili, N., Andersen, D. C., Davis, R. H., \& Kompala, D. S. (1990). Plasmid-encoded protein: The principal factor in the "metabolic burden" associated with recombinant bacteria.Biotechnology and Bioengineering, 35 (7), 668-681. doi:10.1002/bit.260350704

Bienick, M. S., Young, K. W., Klesmith, J. R., Detwiler, E. E., Tomek, K. J., \& Whitehead, T. A. (2014). The interrelationship between promoter strength, gene expression, and growth rate. PLoS ONE, 9 (10). doi:10.1371/journal.pone.0109105

Bower, D. M., \& Prather, K. L. J. (2009). Engineering of bacterial strains and vectors for the production of plasmid DNA. Applied Microbiology and Biotechnology, 82 (5), 805-813. doi:10.1007/s00253-009-1889-8

Chatel, A., Hoare, M., Kumpalume, P., Molek, J. R., Reck, J. M., \& Weber, A. D. (2014). International Publication No. WO2014118220A1 . Geneva, Switzerland: World Intellectual Property Organization,.

Chen, C., Wong, H. E., \& Goudar, C. T. (2018). Upstream process intensification and continuous manufacturing. Current Opinion in Chemical Engineering, 22 , 191-198. doi:10.1016/j.coche.2018.10.006

Chen, Z. Y., Cao, J., Xie, L., Li, X. F., Yu, Z. H., \& Tong, W. Y. (2014). Construction of leaky strains and extracellular production of exogenous proteins in recombinant Escherichia coli .Microbial Biotechnology, 7 (4), 360-370. doi:10.1111/1751-7915.12127

Cheng, J., Wu, D., Chen, S., Chen, J., \& Wu, J. (2011). High-level extracellular production of $\alpha$-cyclodextrin glycosyltransferase with recombinant Escherichia coli BL21 (DE3). Journal of Agricultural and Food Chemistry, 59 (8), 3797-3802. doi:10.1021/jf200033m

de Marco, A. (2009). Strategies for successful recombinant expression of disulfide bond-dependent proteins in Escherichia coli .Microbial Cell Factories, 8 (26). doi:10.1186/1475-2859-8-26 
DeLisa, M. P., Li, J., Rao, G., Weigand, W. A., \& Bentley, W. E. (1999). Monitoring GFP-operon fusion protein expression during high cell density cultivation of Escherichia coli using an on-line optical sensor. Biotechnology and Bioengineering, 65 (1), 54-64. doi:10.1002/(sici)1097-0290(19991005)65:1<54::Aidbit7>3.0.Co;2-r

Farewell, A., \& Neidhardt, F. C. (1998). Effect of temperature on in vivo protein synthetic capacity in Escherichia coli .Journal of Bacteriology, 180 (17), 4704-4710.

Hoffmann, F., \& Rinas, U. (2001). Plasmid amplification inEscherichia coli after temperature upshift is impaired by induction of recombinant protein synthesis. Biotechnology Letters, 23 (22), 1819-1825. doi:10.1023/A:1012718200638

Jia, B., \& Jeon, C. O. (2016). High-throughput recombinant protein expression in Escherichia coli : current status and future perspectives. Open Biology, 6 (8), 160196-160196. doi:10.1098/rsob.160196

Kateja, N., Agarwal, H., Hebbi, V., \& Rathore, A. S. (2017). Integrated continuous processing of proteins expressed as inclusion bodies: GCSF as a case study. Biotechnology Progress, 33 (4), 998-1009. doi:10.1002/btpr.2413

Klein, T., Heinzel, N., Kroll, P., Brunner, M., Herwig, C., \& Neutsch, L. (2015). Quantification of cell lysis during CHO bioprocesses: Impact on cell count, growth kinetics and productivity. Journal of Biotechnology, 207 , 67-76. doi:10.1016/j.jbiotec.2015.04.021

Kleiner-Grote, G. R. M., Risse, J. M., \& Friehs, K. (2018). Secretion of recombinant proteins from E. coli . Engineering in Life Sciences, 18 (8), 532-550. doi:10.1002/elsc.201700200

Lemmerer, M., Mairhofer, J., Lepak, A., Longus, K., Hahn, R., \& Nidetzky, B. (2019). Decoupling of recombinant protein production fromEscherichia coli cell growth enhances functional expression of plant Leloir glycosyltransferases. Biotechnology and Bioengineering, 116 (6), 1259-1268. doi:10.1002/bit.26934

Liu, Y., \& Huang, H. (2018). Expression of single-domain antibody in different systems. Applied Microbiology and Biotechnology, 102 (2), 539-551. doi:10.1007/s00253-017-8644-3

Mairhofer, J., Scharl, T., Marisch, K., Cserjan-Puschmann, M., \& Striedner, G. (2013). Comparative transcription profiling and in-depth characterization of plasmid-based and plasmid-free Escherichia coli expression systems under production conditions. Applied and Environmental Microbiology, 79 (12), 3802-3812. doi:10.1128/AEM.00365-13

Mairhofer, J., Striedner, G., Grabherr, R., \& Wilde, M. (2016).European Patent No. EP3289088B1 . Munich, Germany: European Patent Office,.

Mergulhão, F. J. M., \& Monteiro, G. A. (2007). Periplasmic Targeting of Recombinant Proteins in Escherichia coli . In (pp. 47-61). Totowa, NJ: Humana Press.

Mergulhão, F. J. M., Summers, D. K., \& Monteiro, G. A. (2005). Recombinant protein secretion in Escherichia coli .Biotechnology Advances, 23 (3), 177-202. doi:10.1016/j.biotechadv.2004.11.003

Müller, J. M., Wetzel, D., Flaschel, E., Friehs, K., \& Risse, J. M. (2016). Constitutive production and efficient secretion of soluble full-length streptavidin by an Escherichia coli 'leaky mutant'. Journal of Biotechnology, 221 , 91-100. doi:10.1016/j.jbiotec.2016.01.032

Neidhardt, F. C., \& Umbarger, H. E. (1996). Chemical Composition of Escherichia coli . In F. C. Neidhardt (Ed.), Escherichia coli and Salmonella: Cellular and Molecular Biology . Washington, D.C.: ASM Press.

Orr, V., Scharer, J., Moo-Young, M., Honeyman, C. H., Fenner, D., Crossley, L., . . Chou, C. P. (2012). Integrated development of an effective bioprocess for extracellular production of penicillin G acylase in Escherichia coli and its subsequent one-step purification. Journal of Biotechnology, 161 (1), 19-26. doi:10.1016/j.jbiotec.2012.05.013 
Rinas, U., \& Hoffmann, F. (2004). Selective leakage of host-cell proteins during high-cell-density cultivation of recombinant and non-recombinant Escherichia coli . Biotechnology Progress, 20 (3), 679-687. doi:10.1021/bp034348k

Rodríguez-Carmona, E., Cano-Garrido, O., Dragosits, M., Maurer, M., Mader, A., Kunert, R., .. . Vázquez, F. (2012). Recombinant Fab expression and secretion in Escherichia coli continuous culture at medium cell densities: Influence of temperature. Process Biochemistry, 47 (3), 446-452. doi:10.1016/j.procbio.2011.11.024

Rosano, G. L., \& Ceccarelli, E. A. (2014). Recombinant protein expression in Escherichia coli : Advances and challenges.Frontiers in Microbiology, 5 (APR), 1-17. doi:10.3389/fmicb.2014.00172

Rosano, G. L., Morales, E. S., \& Ceccarelli, E. A. (2019). New tools for recombinant protein production in Escherichia coli : A 5-year update. Protein Science, 28 (8), 1412-1422. doi:10.1002/pro.3668

Shin, C. S., Hong, M. S., Bae, C. S., \& Lee, J. (1997). Enhanced production of human mini-proinsulin in fed-batch cultures at high cell density of Escherichia coli BL21(DE3)[pET-3aT2M2].Biotechnology Progress, 13 (3), 249-257. doi:10.1021/bp970018m

Shin, H. D., \& Chen, R. R. (2008). Extracellular recombinant protein production from an Escherichia coli lpp deletion mutant.Biotechnology and Bioengineering, 101 (6), 1288-1296. doi:10.1002/bit.22013

Shokri, A., Sanden, A. M., \& Larsson, G. (2002). Growth rate-dependent changes in Escherichia coli membrane structure and protein leakage. Applied Microbiology and Biotechnology, 58 (3), 386-392. doi:10.1007/s00253001-0889-0

Stargardt, P., Feuchtenhofer, L., Cserjan-Puschmann, M., Striedner, G., \& Mairhofer, J. (2020). Bacteriophage inspired growth-decoupled recombinant protein production in Escherichia coli . ACS Synthetic Biology . doi:10.1021/acssynbio.0c00028

Ukkonen, K., Veijola, J., Vasala, A., \& Neubauer, P. (2013). Effect of culture medium, host strain and oxygen transfer on recombinant Fab antibody fragment yield and leakage to medium in shaken E. colicultures. Microbial Cell Factories, 12 , 73. doi:10.1186/1475-2859-12-73

Vind, J., Sorensen, M. A., Rasmussen, M. D., \& Pedersen, S. (1993). Synthesis of proteins in Escherichia coli is limited by the concentration of free ribosomes. Expression from reporter genes does not always reflect functional mRNA levels. Journal of Molecular Biology, 231 (3), 678-688. doi:10.1006/jmbi.1993.1319

Voulgaris, I., Finka, G., Uden, M., \& Hoare, M. (2015). Enhancing the selective extracellular location of a recombinant Escherichia coli domain antibody by management of fermentation conditions. Applied Microbiology and Biotechnology, 99 (20), 8441-8453. doi:10.1007/s00253-015-6799-3

Wang, L., Chen, S., \& Wu, J. (2018). Cyclodextrin enhanced the soluble expression of Bacillus clarkii $\gamma$-CGTase in Escherichia coli . BMC Biotechnology, 18 (1), 72. doi:10.1186/s12896-018-0480-8

Wurm, D. J., Marschall, L., Sagmeister, P., Herwig, C., \& Spadiut, O. (2017). Simple monitoring of cell leakiness and viability inEscherichia coli bioprocesses - A case study. Engineering in Life Sciences, 17 (6), 598-604. doi:10.1002/elsc.201600204

Wurm, D. J., Slouka, C., Bosilj, T., Herwig, C., \& Spadiut, O. (2017). How to trigger periplasmic release in recombinant Escherichia coli : A comparative analysis. Engineering in Life Sciences, 17 (2), 215-222. doi:10.1002/elsc.201600168

Yoon, S. H., Kim, S. K., \& Kim, J. F. (2010). Secretory Production of Recombinant Proteins in Escherichia coli . Recent Patents on Biotechnology, 4 (1), 23-29. doi:10.2174/187220810790069550

Zhou, Y., Lu, Z., Wang, X., Selvaraj, J. N., \& Zhang, G. (2018). Genetic engineering modification and fermentation optimization for extracellular production of recombinant proteins using Escherichia coli . Applied Microbiology and Biotechnology, 102 (4), 1545-1556. doi:10.1007/s00253-017-8700-z 


\section{List of Figures}

Figure 1 Biomass yield in cultivations of X-press (A) and BL21(DE3) (B) producing SpA.

Figure 2 Intra- and extracellular soluble SpA titer in cultivations of X-press (A) and BL21(DE3) (B). Annotations above the columns represent leakiness in percent.

Figure 3 Cell lysis in cultivations of the X-press strain producing SpA.
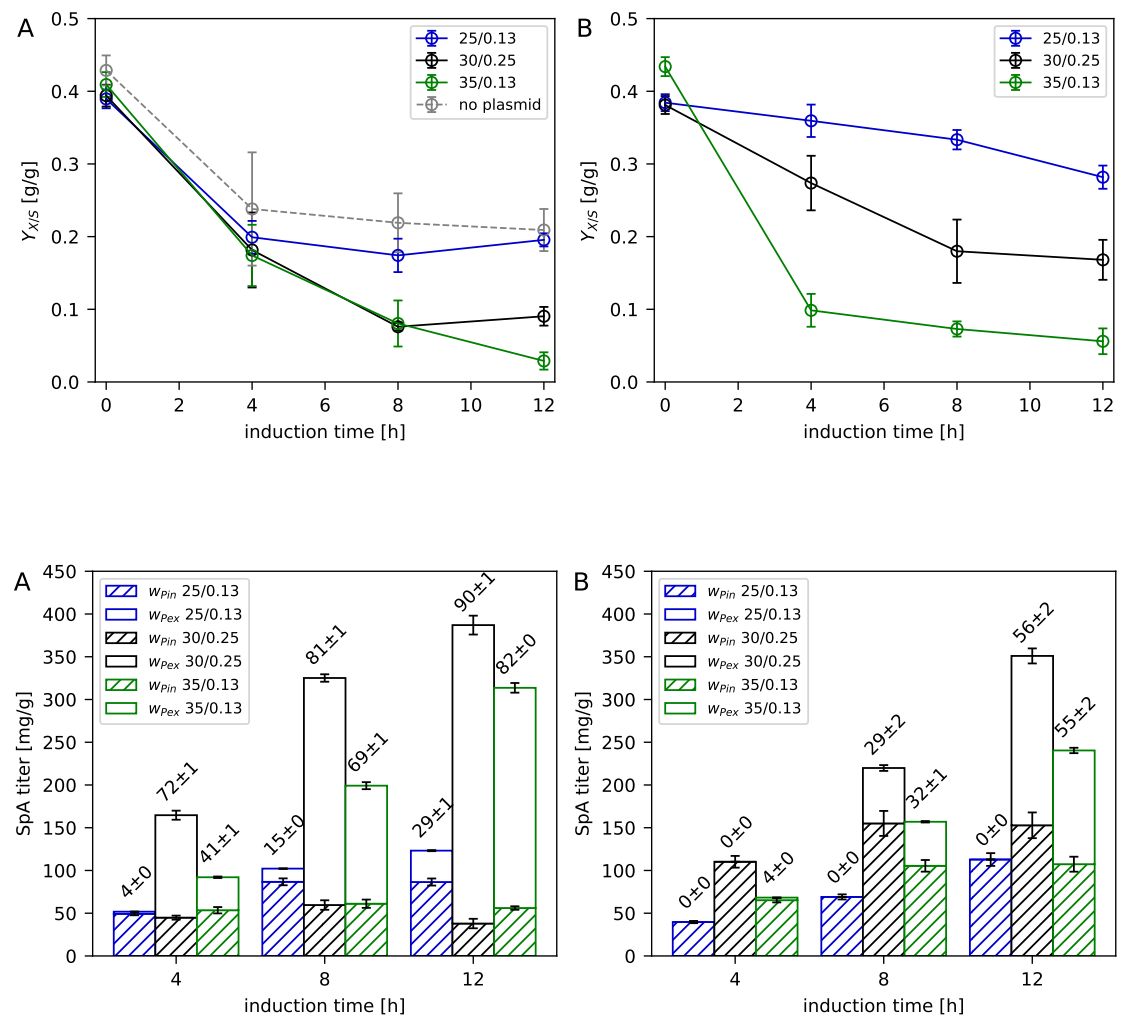


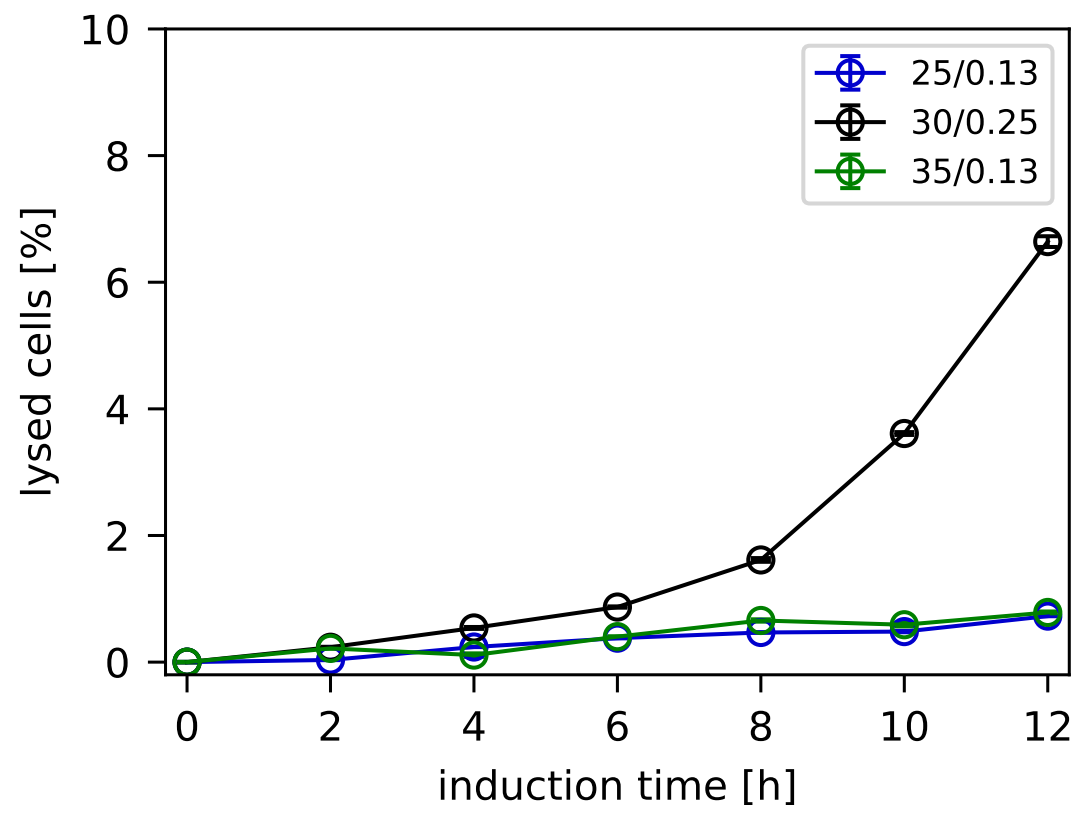

